\title{
Natural skin-whitening compounds for the treatment of melanogenesis (Review)
}

\author{
WENHUI QIAN ${ }^{1,2}$, WENYA LIU ${ }^{1}$, DONG ZHU ${ }^{2}$, YANLI CAO ${ }^{1}$, ANFU TANG ${ }^{1}$, GUANGMING GONG ${ }^{1}$ and HUA SU ${ }^{1}$ \\ ${ }^{1}$ Department of Pharmaceutics, Jinling Hospital, Nanjing University School of Medicine; \\ ${ }^{2}$ School of Pharmacy, Nanjing University of Chinese Medicine, Nanjing, Jiangsu 210002, P.R. China
}

Received June 14, 2019; Accepted March 17, 2020

DOI: $10.3892 /$ etm.2020.8687

\begin{abstract}
Melanogenesis is the process for the production of melanin, which is the primary cause of human skin pigmentation. Skin-whitening agents are commercially available for those who wish to have a lighter skin complexions. To date, although numerous natural compounds have been proposed to alleviate hyperpigmentation, insufficient attention has been focused on potential natural skin-whitening agents and their mechanism of action from the perspective of compound classification. In the present article, the synthetic process of melanogenesis and associated core signaling pathways are summarized. An overview of the list of natural skin-lightening agents, along with their compound classifications, is also presented, where their efficacy based on their respective mechanisms of action on melanogenesis is discussed.
\end{abstract}

\section{Contents}

1. Introduction

2. Melanogenesis

3. Core signaling pathways in the regulation of melanogenesis

4. Naturally occurring skin-whitening agents for inhibiting melanogenesis

5. Conclusions

\section{Introduction}

Lighter skin tone has long been associated with youth and beauty among a variety of Asian cultures. Investment in

Correspondence to: Dr Guangming Gong or Mrs. Hua Su, Department of Pharmaceutics, Jinling Hospital, Nanjing University School of Medicine, 305 Zhongshan Road, Nanjing, Jiangsu 210002, P.R. China

E-mail: gonggm@126.com

E-mail: suhuash@sina.com

Key words: melanogenesis, skin-whitening agents, natural sources, tyrosinase skin-whitening agents, boosted by markets in Asian countries, especially those in China, India and Japan, is increasing annually (1). Skin color is influenced by a number of intrinsic factors, including skin types and genetic background, and extrinsic factors, including the degree of sunlight exposure and environmental pollution (2-4). Skin color is determined by the quantity of melanosomes and their extent of dispersion in the skin (5). Under physiological conditions, pigmentation can protect the skin against harmful UV injury. However, excessive generation of melanin can result in extensive aesthetic problems, including melasma, pigmentation of ephelides and post-inflammatory hyperpigmentation $(1,6)$. Traditional pharmacological agents, including corticosteroids, hydroquinone and aminomercuric chloride, lighten skin tone through the inhibition of either melanocyte maturation or interference with the process of melanogenesis. However, most if not all of the aforementioned agents are closely associated with adverse effects including prickling sensation, contact dermatitis, irritation, high toxicity and sensitivity (7-10). Therefore, recent research by cosmetic companies and research institutions has been focusing on the development of novel whitening agents that selectively suppress the activity of tyrosinase (TYR) to reduce hyperpigmentation whilst avoiding cytotoxicity to normal, healthy melanocytes. As a result, natural skin whitening compounds are currently garnering significant attention in the cosmetic and medical industry $(11,12)$.

The present review summarizes the biosynthetic process of melanogenesis and the associated core regulatory signaling pathways. It also reviews natural skin-whitening agents in terms of their compound classification and discusses their efficacy based on their mechanism of action on melanogenesis. In addition, an overview of the current research methodology applied for the evaluation of compound bioactivity is provided. The aim of the present review is to provide informative guidance for the development of safe and effective depigmenting agents for use in the cosmetic industry.

\section{Melanogenesis}

Melanin is mainly produced by melanocytes that are localized in the epidermis, the outermost layer of the skin; it is also this layer that determines skin color in humans (4). Melanin is primarily synthesized in melanosomes, which function as specialized organelles in melanocytes. Melanogenesis 
is a complex process that involves a series of enzymatic and chemical reactions inside the melanosomes, resulting in the production of two types of melanin: Eumelanin and pheomelanin. Eumelanin is an insoluble polymer that is dark brown-black in color, whereas pheomelanin is a soluble polymer light red-yellow in color that also contain sulfur (13). Both eumelanin and pheomelanin are formed by the conjugation of cysteine or glutathione (14-16). To gain an understanding of the mechanism of whitening agents, a summary of the signaling pathways associated with skin melanogenesis is presented in Fig. 1. The pigmentation process starts with the oxidation of L-tyrosine to L-dopaquinone (DQ) in the presence of the rate-limiting enzyme TYR. Following DQ formation, the resulting quinone undergoes intramolecular cyclization and oxidation, where it serves as a substrate for the synthesis of eumelanin and pheomelanin $(17,18)$. During the process of melanogenesis, hydroxylation of L-tyrosine to form L-3,4-dihydroxyphenylalanine (L-DOPA) is the rate-limiting step of the whole process, which is catalyzed by TYR.

\section{Core signaling pathways in the regulation of melanogenesis}

Melanogenesis is a complex process that is modulated by a network of pivotal signaling cascades and transcription factors, which is controlled at different levels. In particular, modulation of TYR activity is the most commonly applied strategy for the clinical intervention of pigmentation disorders. Since naturally occurring inhibitors of melanogenesis usually garner more attention compared with chemically synthesized compounds due to the cosmetic demands of consumers, the present review focuses on natural compounds that have been documented to exhibit skin-whitening effects through the inhibition of TYR activity. The three core signal pathways involved in the regulation of melanogenesis are: i) melanocortin-1 receptor (MC1R) signaling; ii) the Wnt/ $\beta$-catenin signaling pathway; and iii) the tyrosine kinase receptor KIT/stem cell factor (SCF) pathway, all of which converge downstream to activate the master regulator-microphthalmia-associated transcription factor (MITF) (Fig. 2) (19). The following sections will describe the genetic and molecular modulators that are involved in the control of melanogenesis by these three key pathways.

$\alpha$-melanocyte-stimulating hormone ( $\alpha-M S H)-M C 1 R$ signaling pathway. $\alpha-\mathrm{MSH}$ is a precursor polypeptide derived from pro-opiomelanocortin that can modulate pigmentation through paracrine action, whilst MC1R is a member of the G-protein-coupled receptor family (20). $\alpha$-MSH binding to $\mathrm{MC1R}$ results in the activation of adenylyl cyclase, increasing the intracellular levels of cAMP and subsequently upregulating TYR, tyrosinase related protein-1 (TRP-1) and tyrosinase related protein-2 (TRP-2) expression. The biological effects downstream of cAMP elevation have been previously demonstrated to be predominately mediated by cAMP-dependent protein kinase (PKA), which phosphorylates cAMP-response element (CRE) binding protein (CREB) (21). However, it has also been suggested that neither TRP-1 nor TRP-2 have cAMP response elements in their respective promoter regions. Evidence has indicated that regulating the gene expression of TRP-1 and TRP-2 by cAMP is directly associated with MITF, which binds to the M-box sequence (AGTCATGTG
CT) located in the tyrosinase distal elements (TDEs) after its activation (22). Since the promoter region of MITF contains the consensus CRE sequence, the expression of MITF can also be increased by $\alpha$-MSH stimulation in a cAMP-dependent manner (23). This demonstrated that the $\alpha$-MSH-MC1R signaling pathway induces melanin production predominantly by elevating intracellular cAMP levels, and the inhibition of which can exert inhibitory effects on melanogenesis.

Wnt signaling pathway. The Wnt signaling pathway has been previously reported to serve an important role in melanogenesis $(24,25)$. Wnt ligands bind to Frizzled receptors on the cell surface, resulting in the increased stability of cytoplasmic $\beta$-catenin, and its subsequent translocation into the nucleus, where it activates the transcription of MITF by interplay with lymphoid enhancer-binding factor 1 (LEF1)/T-cell factor (LEF1/TCF) (26). Previous studies on melanocytes suggest that $\beta$-catenin and LEF1 synergistically regulate the $\mathrm{M}$ promoter activity of MITF via LEF1 binding sites, which upregulate MITF expression in melanoma $(27,28)$. By regulating MITF transcription, the Wnt/ $\beta$-catenin signaling pathway can control the expression of TYR and other pigmentation enzymes.

SCF-KIT signaling pathway. Recent studies have verified the important roles of the SCF-KIT signaling pathway in melanocyte proliferation and differentiation, and the process of melanogenesis $(29,30)$. SCF is a paracrine factor that is secreted by fibroblasts, whereas c-KIT, its receptor, is expressed on melanocytes (31). When SCF binding to its receptor-c-KIT, it stimulates tyrosine kinase activity, resulting in receptor auto-phosphorylation to initiate signal transduction $(32,33)$. c-KIT phosphorylation directly activates p38 mitogen-activated protein kinase (MAPK), a member of the MAP kinase family, which in turn phosphorylates CREB and subsequently activates MITF to promote TYR transcription (34). c-KIT can also activate ERK. c-KIT-mediated ERK signaling pathway can induces CREB phosphorylation to activate melanin synthesis on one hand, and on the other hand, the activation of ERK signaling has been demonstrated to phosphorylate MITF at the serine 73 residue, which leads to the ubiquitination and degradation of MITF, this is the feedback mechanism of the ERK pathway to regulate melanin production $(3,35)$. In addition to p38 MAPK and ERK, c-KIT activation is associated with the phosphoinositide 3-kinase (PI3K) signaling pathway, which not only regulates cell survival but also causes pigmentation by activating the serine/threonine-specific protein kinase AKT. Downstream, PI3K activation leads to the phosphorylation of glycogen synthase kinase $3 \beta$ (GSK-3 $\beta$ ) to increase MITF activity (36). Therefore, inhibitors of the SCF-KIT signaling pathway can potentially exhibit anti-melanogenesis activity.

$M I T F$. MITF serves as the central hub of the regulatory network of melanin synthesis that is comprised of numerous transcription factors and signaling pathways that modulate the survival, proliferation and differentiation of melanoblasts and melanocytes (37). The MITF gene contains multiple promoters, the M promoter is one of such promoters, which is located adjacent to the common downstream exons and is targeted by several transcriptional factors, including CREB, paired box gene 3 


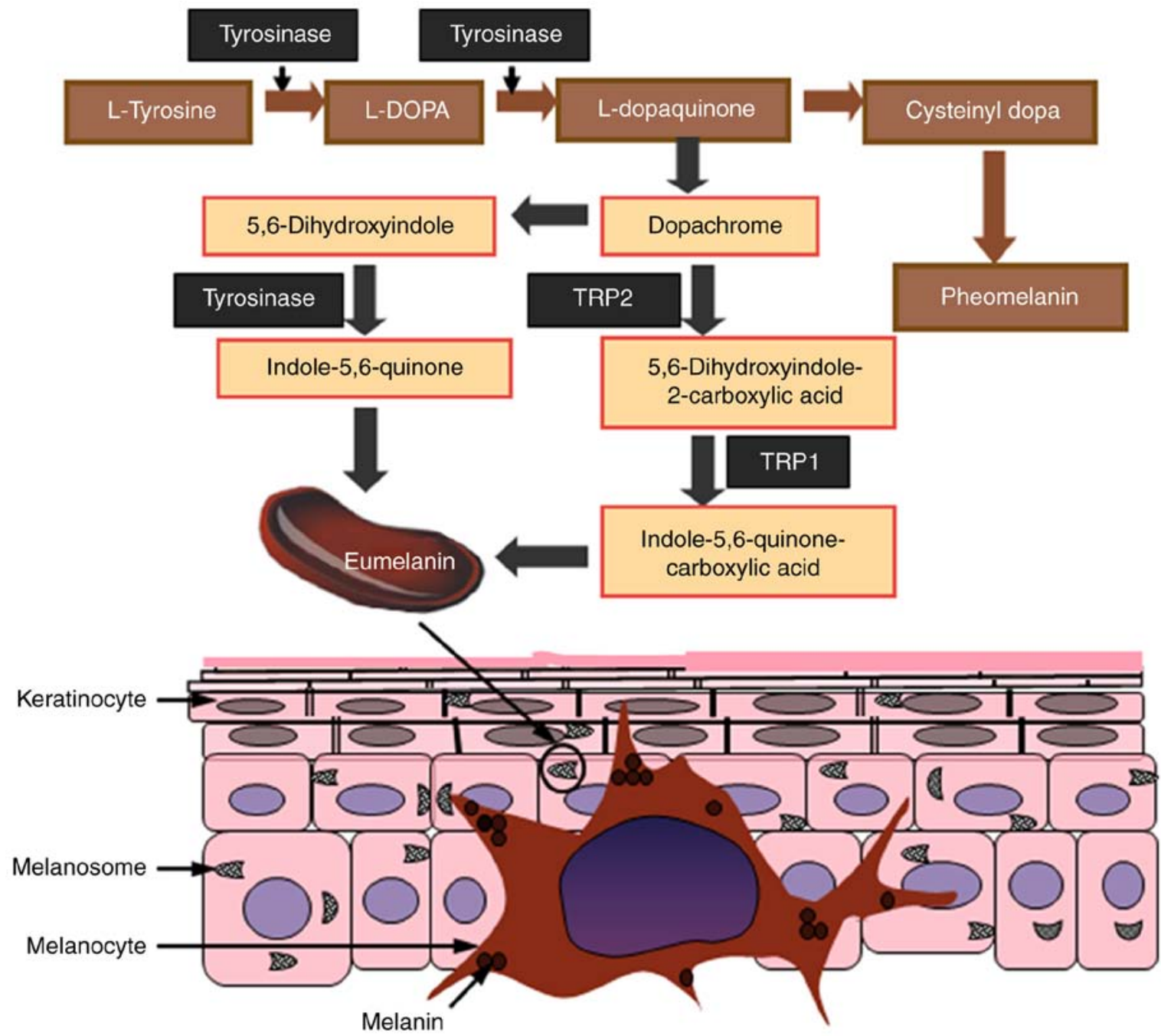

Figure 1. Melanogenesis and transport. Melanocytes are located on the basal layer of the skin, which synthesizes melanin. Eumelanin and pheomelanin are produced in melanosomes, a specialized organelle within melanocytes, through a series of reactions that are catalyzed by melanogenic enzymes. The synthetic pathways are divided into two branches: Eumelanogenesis and pheomelanogenesis. Melanocytes transport the melanin pigments produced by melanosomes through their elongated dendrites into neighboring keratinocytes in the epidermis layer. TRP1, tyrosinase related protein-1; TRP2, tyrosinase related protein-2; L-DOPA, L-3,4-dihydroxyphenylalanine.

(PAX3), LEF1/TCF, SRY-related HMG-box 10 (SOX10), SOX9 and MITF itself (38). In melanocytes, these transcription factors bind to the promoter of MITF-M to regulate MITF expression whilst controlling the transcription of several important genes. These genes are not only related to the production of melanin, including TYR, TRP-1 and TRP-2, but are also linked to the regulation of melanocyte differentiation, proliferation and cell cycle progression. Cyclin-dependent kinase 2 (CDK2), B-cell lymphoma-2 (BCL-2) and Hypoxia-inducible factor 1-alpha (HIF-1 $\alpha$ ) are such genes that are regulated by MITF. In addition, MAPK, ribosomal S6 kinase (RSK), glycogen synthase

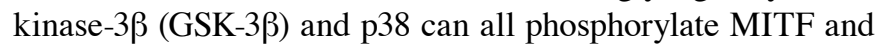
simultaneously modulate its transcriptional activity in response to specific environmental cues (39-43).

\section{Naturally occurring skin-whitening agents for inhibiting melanogenesis}

Naturally occurring skin-whitening agents exert their effects by regulating melanin production through a number of mecha- nisms, including inhibiting the expression and activity of TYR and suppressing the uptake and distribution of melanosomes. In the cosmetics industry, since skin-whitening compounds from natural sources are usually more appealing to consumers, a greater demand exists for inhibitors of melanogenesis derived from herbal plants that prevent hyperpigmentary disorders. Naturally occurring bioactive compounds, including flavonoids, terpenoids, polysaccharides and coumarin derivatives, all of which have been previously demonstrated to exhibit antioxidant and anti-inflammatory properties, are now becoming increasing recognized to possess anti-melanogenesis functions $(44,45)$. Therefore, this section focuses on the natural active skin-whitening agents that are currently known based on their compound classification along with their mechanism of action on melanogenesis.

Transcriptional control of TYR expression via MITF. MITF serves an indispensable role in melanogenesis as it controls the transcription of TYR and other pigmentation-associated enzymes (46-48). Naturally occurring bioactive compounds 


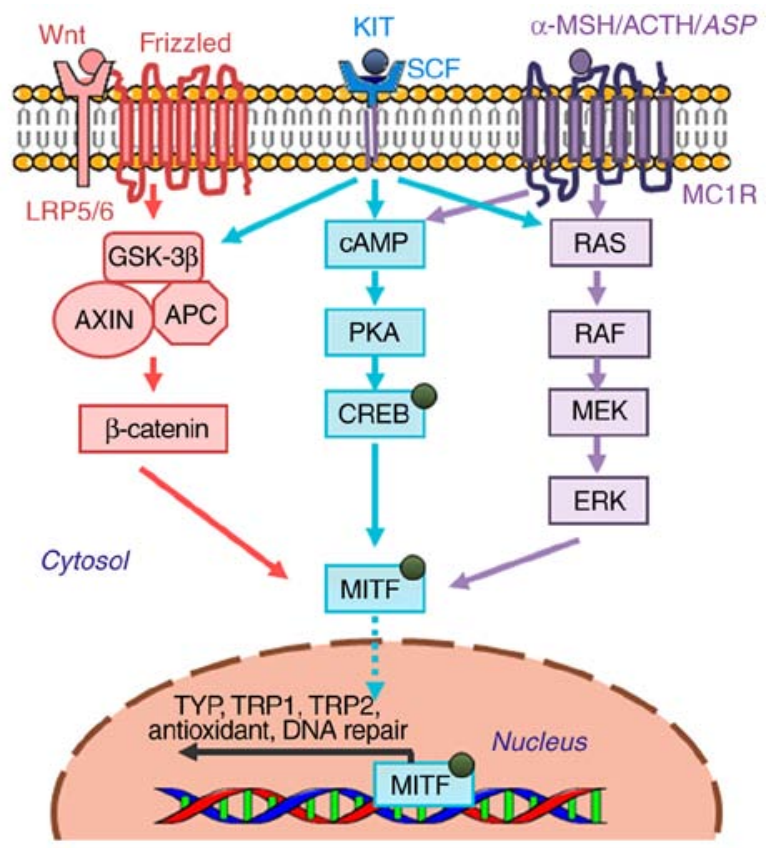

Figure 2. Core molecular pathways associated with the regulation of melanin production in melanocytes. Genes encoding specific melanogenic enzymes, including TYP, TRP1 and TRP2, are regulated by the MITF transcription factor, which is in turn regulated by a number of important signaling pathways, including $\alpha-\mathrm{MSH} / \mathrm{MC1F}$ (purple), KIT/SCF (blue) and Wnt/frizzled (red). Signal transduction is mediated by cAMP/PKA, RAS/ MEK/ERK and $\beta$-catenin pathways. cAMP, cyclic AMP; MEK, MAPK/ ERK kinase; Wnt, wingless-related integration site; LRP5/6, low-density lipoprotein receptor-related protein 5/6; GSK-3 $\beta$, glycogen synthase kinase-3 $\beta$; AXIN, axis inhibitor; APC, adenomatous polyposis coli; SCF, stem cell factor; MC1R, melanocyte-specific melanocortin-1 receptor; $\alpha$-MSH, $\alpha$-melanocyte-stimulating hormone; ACTH, adrenocorticotropic hormone; ASP, agonist stimulating protein; TRP1, tyrosinase related protein-1; TRP2, tyrosinase related protein-2; PKA, protein kinase A; MITF, microphthalmia-associated transcription factor; CREB, cAMP response element binding protein.

have now been reported to exert an anti-melanogenesis function by interfering with signaling pathways to downregulate MITF expression. Among them, phenolic compounds, including [6]-Shogaol (49), derived from Heracleum moellendorffi Hance extracts (50), the ethyl acetate fraction of Oroxylum indicum Vent. seeds (51) and 2-[4-(3-hydroxypropyl)-2methoxyphenoxy]-1,3-propanediol (35) from Juglans mandshurica plants, inhibit melanogenesis by mediating the degradation of MITF in a manner that is associated with ERK signaling. By contrast, other phenolic compounds (52-55) exert anti-melanogenic properties by downregulating the cAMP/CREB signaling pathway and/or activating related caspases to trigger apoptosis of melanocyte cells (Table I). Flavonoids, including isoorientin, catechin, coumaric acid and kaempferol-7-O-D-glucuronide, derived from Gentiana (56), Phyllostachys nigra (57), Cryptotaenia japonica (57) and dried pomegranate concentrate powder (58) exhibit skin-whitening effects by downregulating PKA/CREB-mediated MITF expression. A list of other bioactive compounds, including terpenoids, polysaccharides and lignanoids, and their respective molecular mechanism of action on the melanogenesis pathway is provided in Table I $(49,59-72)$. It can be observed that bioactive compounds are able to suppress MITF or TYR activity by either binding to transcription factors directly or by inhibiting melanogenic pathways upstream, including that of cAMP/PKA, ERK, Wnt/ $\beta$-catenin and MAPK. Therefore, these aforementioned compounds represent promising skin-whitening agents, but those targeting TYR gene expression are not recommended for clinical use mainly for their non-specific effects through intracellular signaling cascades (73).

TYR modulation. TYR is a popular target for the development of skin-whitening agents due to its position at the rate-limiting step of the melanogenesis pathway. Additionally, TYR inhibitors have highly specificity for targeting melanogenesis, reducing the risk of side effects. Therefore, TYR inhibitors remain as the most successful and commonly applied skin-whitening agents. The majority of the naturally occurring compounds currently applied are botanical inhibitors of TYR, where their mechanism of action mainly entails two processes.

Inhibition of TYR catalytic activity. A number of studies have reported TYR inhibitors from natural sources, most of which are originate from Asia. Table II provides a summary of studies that have previously applied such types of TYR inhibitors. In a substantial number of these studies, mushroom TYR has been used as the protein model, and the $\mathrm{IC}_{50}$ values of the prospective TYR inhibitor were compared with those of other established inhibitors, including kojic acid and arbutin. TYR is a multi-functional type-3 copper-containing glycoprotein that is located on the membrane of the melanosome $(1,74)$. Structurally, the active site of TYR consists two copper ions surrounded by three histidine residues (75). Anthraquinones, flavonoids and phenylpropanoids can serve as competitive inhibitors of TYR due chemical structures similar to those of L-tyrosine or L-DOPA (76,77).

Within the quinone family of compounds, the most frequently applied skin-whitening agents are hydroquinone (HQ) $(78,79)$ and arbutin $(80,81)$. Although HQ can function as an alternative substrate for TYR, the subsequent enzymatic reaction results in the production of reactive oxygen species (ROS), which is thought to be responsible for its skin-lightening properties, with possible associated side effects including leukoderma and exogenous ochronosis $(82,83)$. Therefore, HQ has been banned in the EU, USA and a number of African and Asian countries (5). By contrast, arbutin is an effective agent for treating for hyperpigmentation in the cosmetics industry, which is also commonly applied as a positive control for melanogenesis studies.

Flavonoid compounds, including epigallocatechin gallate (84), quercetin (85), aloesin $(86,87)$, hydroxystilbene derivates and licorice extracts are used for hyperpigmentation due to the ability to remove ROS and to chelate metals ions at the active sites of metalloenzymes (88). The hydroxystilbene family of compounds, which includes resveratrol as a well-known example, is the most efficient at alleviating hyperpigmentation compared with other families of flavonoid compounds. Resveratrol, which is found in a wide variety of plants such as grapes, exhibits potent inhibitory effects towards TYR $(89,90)$. Regarding other flavonoid compounds, licorice-glabiridin (91), the main component found in the hydrophobic fraction of licorice extracts (92), has previously been demonstrated to exhibit inhibitory activity against TYR 


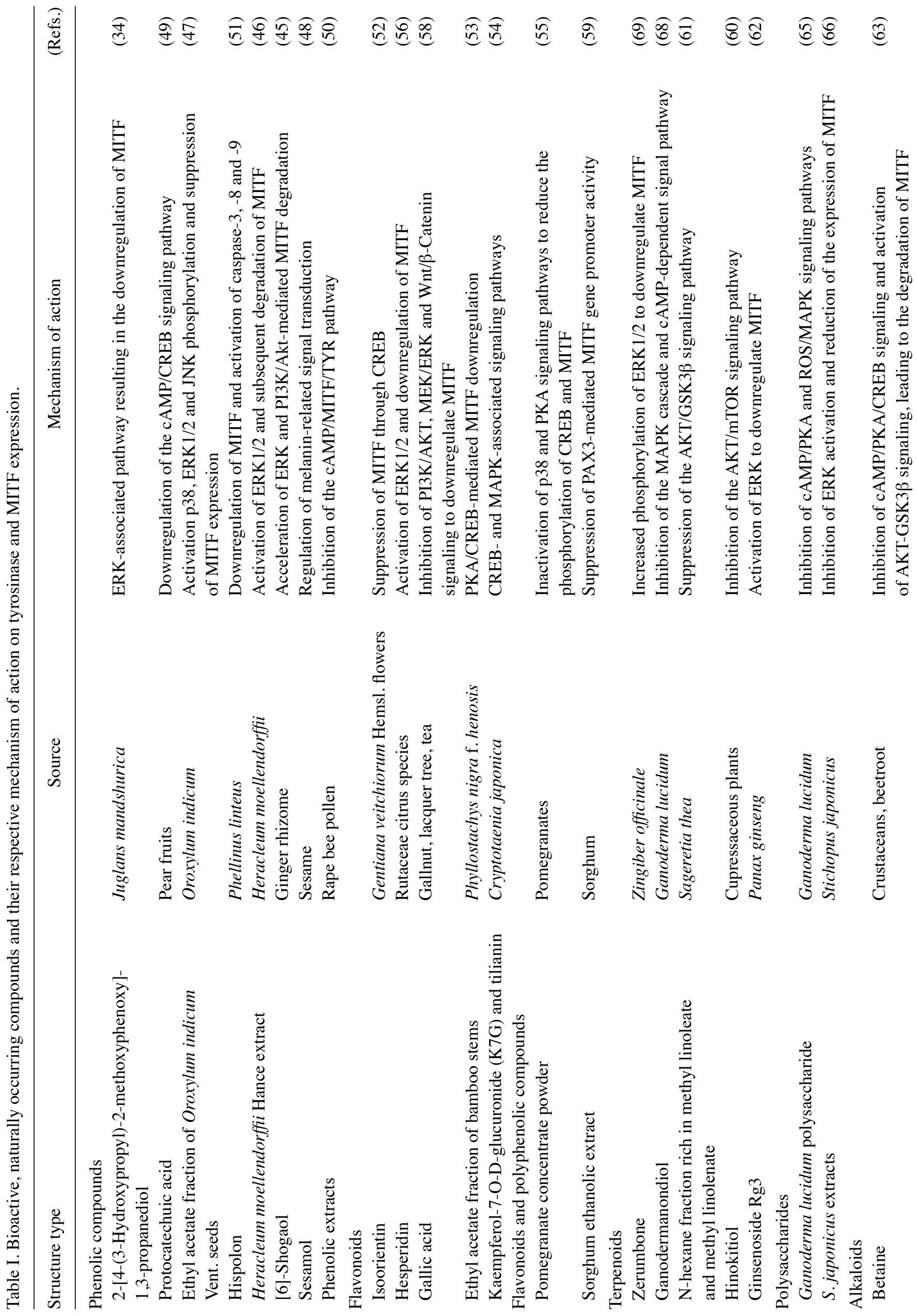


in B16 murine melanoma cells $(93,94)$. A list of other recently discovered flavonoids that have been reported to inhibit the activity of TYR is shown in Table II (95-104).

Phenylpropanoids and olefinic unsaturated compounds, which include ferulic acid, benzaldehyde (105), astaxanthin, curcumin and cinnamic acid esters (106), have been revealed to exert inhibitory effects on TYR. According to a study by Park et al (107), ferulic acid, one of the main phenolic components found in Tetragonia tetragonioides, suppressed melanin synthesis by reducing the expression of TYR and MITF in B16-F10 cells at concentrations of between 5 and $20 \mu \mathrm{M}$. Additionally, Rao et al (108), Niwano et al (109) and Tu et al (110) demonstrated that astaxanthin and curcumin exhibit suppressive properties on melanin synthesis and cellular TYR activity. Other typical agents with reported inhibitory activities on TYR include kojic acid $(111,112)$, methyl gentisate $(113,114)$, ganodermanondiol $(71,115)$, 10-hydroxy-2-decenoic acid (116), Stichopus japonicus extracts (69) and bis (4-hydroxybenzyl)sulphide (117). Information on their specific respective mechanisms of action are shown in Table II.

Post-translational regulation of TYR. Substances that can regulate melanin synthesis by affecting protein levels of the melanogenic enzymes without any changes in mRNA levels likely regulate the activity of melanogenic enzymes at post-translational levels. Post-translational modification of components in this pathway primarily lead to the inhibition of melanin synthesis. Currently, two main pathways are known for the degradation of TYR, namely proteasomal and lysosomal degradation $(118,119)$. Unsaturated fatty acids, including oleic acid (C18:1), linoleic acid (C18:2) and $\alpha$-linolenic acid (C18:3), have been demonstrated to accelerate the protein degradation of TYR by activating one of these two pathways, leading to anti-melanogenesis activity (120). These agents downregulate intracellular TYR protein levels by promoting ubiquitin-dependent degradation, inhibiting melanin synthesis and suppressing hyperpigmentation. According to previous studies by Park et al (121) and Lee et al (122), terrein, a novel fungal metabolite reduces TYR expression by downregulating MITF in a manner that is dependent on ERK activation, with its inhibitory effects on melanin synthesis prolonged by ubiquitin-mediated proteasomal degradation. By contrast, lysosomes can also target TYR for degradation. Geoditin A, an isomalabaricane triterpene compound derived from the South China Sea Sponge Geodia japonica, has been previously found to suppress melanogenesis by post-translational regulation in the endoplasmic reticulum and the degradation of TYR in the lysosome (123). Resveratrol, a promising pigment-lightening flavonoid found in red wine, was recently found to suppress TYR expression not via the inhibition of MITF expression, but by directly inhibiting TYR activity by a post-translational modification that reduces the levels of fully mature TYR protein (119). Retention of misfolded TYR proteins in the endoplasmic reticulum results in the loss of pigmentation, which has also been proposed to be one of the major post-translational mechanisms responsible for the effects of resveratrol.

Inhibition of melanin dispersion. Following melanin synthesis, one key step of melanogenesis in the skin is the translocation 


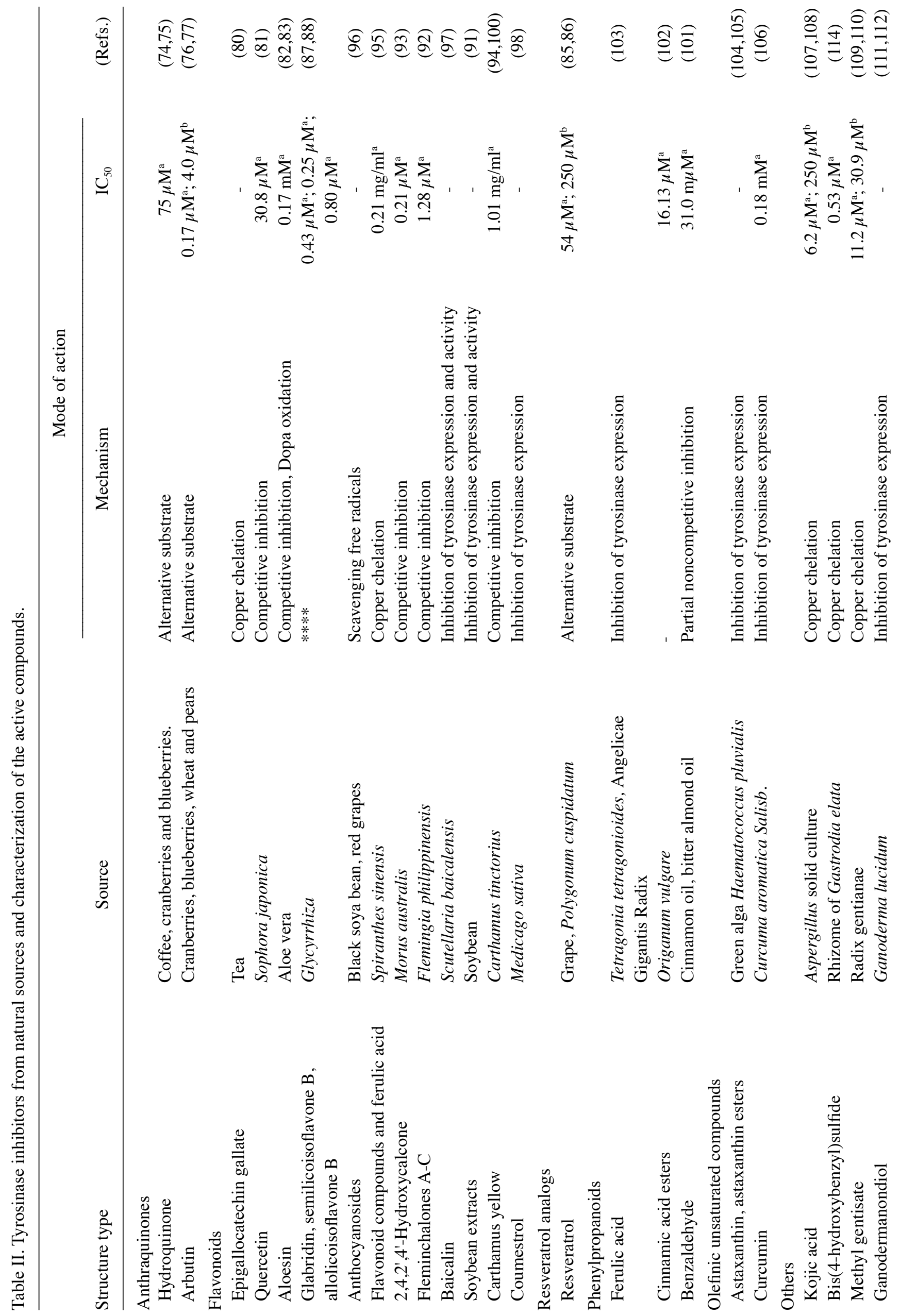


of mature melanosomes into keratinocytes, which are then transported up to the epidermidis where the melanin is dispersed. Therefore, agents that can inhibit the transfer of melanosomes and/or accelerate epidermal turnover can result in the whitening of the skin.

Inhibition of melanosome transfer. A number of studies have previously proposed regulatory mechanisms of melanosome movement in dendrites and interplay between keratinocytes and melanocytes during the transfer process $(124,125)$. In this regard, early skin-whitening compounds, including niacinamide and soybean extracts, are reported to interfere with this process. Niacinamide is has been shown to reduce pigmentation by inhibiting melanosome transfer using a skin-co-culture model (126), whilst soymilk and soybean extracts have been previously suggested to inhibit protease-activated receptor 2 activation in the skin, which may enhance pigment transfer that results in skin whitening $(127,128)$. In addition, it was recently reported that ginsenoside F1 exhibited skin lightening effects by disrupting melanin transfer from the basal layer of melanocytes to the upper layer of keratinocytes (129). Further microscopic research revealed that melanosome transport between cells requires a number of steps, including bidirectional long-range transfer to the apical surface on microtubules, transfer to actin filaments, irreversible short-range transfer by actin dynamics followed by binding to the cell membrane (130). A number of important molecules, including Rab27A, melanophilin (MLPH) /SLP homolog lacking C2 domains-A, synaptotagmin-like protein (SLP) 2A/synaptotagmin 2 and myosin Va are involved in the regulation of melanosome transport $(130,131)$. Kudo et al $(132)$ reported that O-methylated flavones extracted from Scutellaria baicalensis Georgi, such as wogonin, can inhibit the transport of intracellular melanosomes by degrading melanophilin (MLPH), a carrier protein associated with melanosome transport on actin filaments. Additionally, gagunin D, a highly oxygenated diterpenoid from the marine sponge Phorbas sp., was also found to exhibit anti-melanogenic properties by downregulating the expression of proteins associated with melanosome transfer, including Rab27A, MLPH and myosin Va (133). Therefore, these observations suggest that downregulating the expression and activity of the aforementioned proteins associated with melanosome transport may be useful for reversing the process of skin hyperpigmentation.

Inhibition of melanin dispersion and acceleration of epidermal turnover. A number of compounds have been documented to possess the capacity to inhibit the dispersion of melanin granules and accelerate skin turnover, which can result in a lighter skin tone. Topical application of these compounds to the skin has been demonstrated to effectively reduce the visibility of skin spots without affecting their size or quantity, which can be used for treating melasma. Examples of these compounds include $\alpha$-hydroxy acids, salicylic acid, linoleic acid and retinoic acids, which can promote cellular renewal and facilitate the elimination of melanized keratinocytes, leading to the loss of melanin pigmentation $(134,135)$. However, the application of those acids is associated with side effects including erythema, scaling and increased risk of sunburn (136-138). Therefore, current research efforts are mainly focused on the 


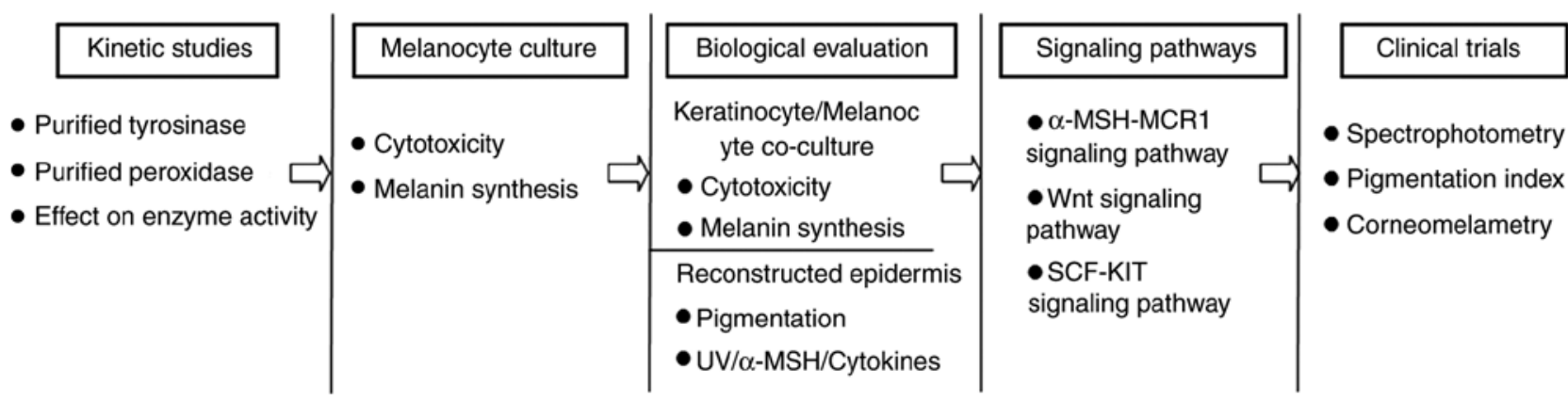

Figure 3. Recommended multi-step research strategy for the evaluation of prospective skin-whitening agents.

discovery of novel components of natural compounds with minimal off-target effects. Liquiritin, a flavonoid glycoside of liquorice, has previously been shown to significantly reduce hyperpigmentation in 20 women with a clinical diagnosis of melasma. The mechanism was proposed to be associated with melanin dispersion mediated by the pyran ring of the flavonoid chemical structure and the acceleration of epidermal turnover (139). This suggest flavonoids to be promising candidates for the development of safe and effective interventions for hyperpigmentation.

\section{Conclusions}

Over the past few years, significant progress has been made on the understanding of melanocyte biology and its underlying mechanism, opening up new research avenues for the discovery of novel melanogenesis inhibitors. In addition to the direct suppression of TYR catalytic activity, other methods for the disruption of melanogenesis include the post-transcriptional control of TYR, regulation of melanosome transfer and the suppression TYR transcription by suppressing upstream signaling pathways. These mainly involve the inhibition of the master regulator MITF, resulting from the reduction of intracellular cAMP levels, increases in cytoplasmic $\beta$-catenin and/or the activation of ERK signaling. Therefore, a large number of inhibitors acting through these aforementioned alternative mechanisms have been successfully identified (73).

Among these inhibitors, a mild, stable, safe and effective compound is sought from natural extracts as a raw material for the development of skin-whitening and skin care products. For such prospective melanogenesis inhibitors, further in vitrol in vivo studies and clinical trials are required to evaluate efficacy and safety. To accelerate the process of drug discovery, a variety of models and methodologies should be applied to assess their potential hypopigmentation activity. From a methodological perspective $(140,141)$, a multi-step process should be adopted for these investigations (Fig. 3). Initial evaluation of whitening properties in vitro should be conducted on purified TYR and/or other melanogenic proteins, followed by the use of melanocyte cultures to examine potential cytotoxic and melanin synthetic effects. For further biological evaluation, co-culture systems and reconstructed skin models should be adopted to screen for the ability of the novel compounds to interfere with the melanogenesis process, especially following stimuli including UV irradiation, exposure to a-MSH or proinflammatory cytokines. In addition, investigation into the regulatory mechanism involved in melanogenesis should be performed. Finally, the in vivo activity of the prospective agents should be evaluated using non-invasive techniques such as UV light photography or spectrophotometry to obtain comparable results $(12,142)$. It is expected that the aforementioned research methodology can provide better opportunities for the development of novel lightening agents that are effective and safe for use in the clinical and cosmetic industries.

Although promising, the use of skin-lightening compounds requires further research due to diverse modes of action or off-target effects (77). Kojic acid and arbutin remain the classic compounds that can be topically used as skin-lightening agents in a clinical setting due to proven efficacy. Additional natural skin-lightening compounds, including mulberry, licorice and lemon extract, are regularly supplemented into skin care products, to strengthen the effect of arbutin or kojic acid $(143,144)$. The ideal skin-lightening cosmetic product should include a formulation that comprises compounds acting on different pathways during the melanogenesis process. This future combination should contain multiple targets and layers, including the control of TYR expression on transcription and protein levels, inhibition of enzymatic activity in the melanogenesis pathway, suppression of melanocyte proliferation and the transport of melanosomes on a cellular level. Although the mechanisms of these inhibitors have been well characterized in vitro, they have not been topically applied in cosmetics and cosmeceuticals. Therefore, further evaluation of their skin-whitening activity in vivo or in parallel human clinical trials are required. In summary, from a clinical point of view, additional mechanistic investigations of the novel natural modulators on melanogenesis are urgently required.

\section{Acknowledgements}

Not applicable.

\section{Funding}

This project was supported by the National Natural Science Foundation of China (grant no. 31671026), the Research Project of Nanjing General Hospital (grant no. 2015056).

\section{Availability of data and materials}

Not applicable. 


\section{Authors' contributions}

GG and HS designed the theme of the review. WL, YC and AT retrieved the relevant literature. WQ wrote and reviewed the article. DZ helped to revise the manuscript and provided important intellectual revision suggestions.

\section{Ethics approval and consent to participate}

Not applicable.

\section{Patient consent for publication}

Not applicable.

\section{Competing interests}

The authors declare that they have no competing interests.

\section{References}

1. Pillaiyar T, Manickam M and Namasivayam V: Skin whitening agents: Medicinal chemistry perspective of tyrosinase inhibitors. J Enzyme Inhib Med Chem 32: 403-425, 2017.

2. Videira IF, Moura DF and Magina S: Mechanisms regulating melanogenesis. An Bras Dermatol 88: 76-83, 2013.

3. D'Mello SA, Finlay GJ, Baguley BC and Askarian-Amiri ME: Signaling pathways in melanogenesis. Int J Mol Sci 17: pii: E1144, 2016.

4. Gillbro JM and Olsson MJ: The melanogenesis and mechanisms of skin-lightening agents--existing and new approaches. Int J Cosmet Sci 33: 210-221, 2011.

5. Desmedt B, Courselle P, De Beer JO, Rogiers V, Grosber M, Deconinck E and De Paepe K: Overview of skin whitening agents with an insight into the illegal cosmetic market in Europe. J Eur Acad Dermatol Venereol 30: 943-950, 2016.

6. Costin GE and Hearing VJ: Human skin pigmentation: Melanocytes modulate skin color in response to stress. Faseb J 21: 976-994, 2007.

7. Takizawa T, Imai T, Onose J, Ueda M, Tamura T, Mitsumori K, Izumi $\mathrm{K}$ and Hirose $\mathrm{M}$ : Enhancement of hepatocarcinogenesis by kojic acid in rat two-stage models after initiation with N-bis (2-hydroxypropyl)nitrosamine or $\mathrm{N}$-diethylnitrosamine. Toxicol Sci 81: 43-49, 2004.

8. García-Gavín J, González-Vilas D, Fernández-Redondo V and Toribio J: Pigmented contact dermatitis due to kojic acid. A paradoxical side effect of a skin lightener. Contact Dermatitis 62: 63-64, 2010.

9. Chung KW, Jeong HO, Jang EJ, Choi YJ, Kim DH, Kim SR, Lee KJ, Lee HJ, Chun P, Byun Y, et al: Characterization of a small molecule inhibitor of melanogenesis that inhibits tyrosinase activity and scavenges nitric oxide (NO). Biochim Biophys Acta 1830: 4752-4761, 2013.

10. Hong YH, Jung EY, Noh DO and Suh HJ: Physiological effects of formulation containing tannase-converted green tea extract on skin care: Physical stability, collagenase, elastase and tyrosinase activities. Integr Med Res 3: 25-33, 2014.

11. Chiang HM, Chien YC, Wu CH, Kuo YH, Wu WC, Pan YY, $\mathrm{Su} \mathrm{YH}$ and Wen KC: Hydroalcoholic extract of Rhodiola rosea L. (Crassulaceae) and its hydrolysate inhibit melanogenesis in B16F0 cells by regulating the $\mathrm{CREB} / \mathrm{MITF} /$ tyrosinase pathway. Food Chem Toxicol 65: 129-139, 2014.

12. Lajis AFB and Ariff AB: Discovery of new depigmenting compounds and their efficacy to treat hyperpigmentation: Evidence from in vitro study. J Cosmet Dermatol 18: 703-727, 2019.

13. Ito $\mathrm{S}$ and Wakamatsu K: Quantitative analysis of eumelanin and pheomelanin in humans, mice and other animals: A comparative review. Pigment Cell Res 16: 523-531, 2003.

14. Slominski A, Tobin DJ, Shibahara S and Wortsman J: Melanin pigmentation in mammalian skin and its hormonal regulation. Physiol Rev 84: 1155-1228, 2004.

15. Schiaffino MV: Signaling pathways in melanosome biogenesis and pathology. Int J Biochem Cell Biol 42: 1094-1104, 2010.
16. Pillaiyar T, Manickam M and Jung SH: Inhibitors of melanogenesis: A patent review (2009 - 2014). Expert Opin Ther Pat 25: 775-788, 2015

17. Hearing VJ and Jiménez M: Mammalian tyrosinase-the critical regulatory control point in melanocyte pigmentation. Int J Biochem 19: 1141-1147, 1987.

18. Halaban R, Patton RS, Cheng E, Svedine S, Trombetta ES, Wahl ML, Ariyan S and Hebert DN: Abnormal acidification of melanoma cells induces tyrosinase retention in the early secretory pathway. J Biol Chem 277: 14821-14828, 2002.

19. Hou L, Panthier JJ and Arnheiter H: Signaling and transcriptional regulation in the neural crest-derived melanocyte lineage: Interactions between KIT and MITF. Development 127: 5379-5389, 2000.

20. Ryu S, Johnson A, Park Y, Kim B, Norris D, Armstrong CA and Song PI: The alpha-melanocyte-stimulating hormone suppresses TLR2-mediated functional responses through IRAK-M in normal human keratinocytes. PLoS One 10: e0136887, 2015.

21. Edelman AM, Blumenthal DK and Krebs EG: Protein serine/threonine kinases. Annu Rev Biochem 56: 567-613, 1987.

22. Yasumoto K, Yokoyama K, Shibata K, Tomita Y and Shibahara S: Microphthalmia-associated transcription factor as a regulator for melanocyte-specific transcription of the human tyrosinase gene. Mol Cell Biol 14: 8058-8070, 1994.

23. Bertolotto C, Abbe P, Hemesath TJ, Bille K, Fisher DE, Ortonne JP and Ballotti R: Microphthalmia gene product as a signal transducer in cAMP-induced differentiation of melanocytes. J Cell Biol 142: 827-835, 1998.

24. Zhu PY, Yin WH, Wang MR, Dang YY and Ye XY: Andrographolide suppresses melanin synthesis through Akt/GSK3 $\beta / \beta$-catenin signal pathway. J Dermatol Sci 79: 74-83, 2015.

25. Hwang I, Park JH, Park HS, Choi KA, Seol KC, Oh SI, Kang S and Hong S: Neural stem cells inhibit melanin production by activation of Wnt inhibitors. J Dermatol Sci 72: 274-283, 2013.

26. Steingrimsson E, Copeland NG and Jenkins NA: Melanocytes and the microphthalmia transcription factor network. Annu Rev Genet 38: 365-411, 2004

27. Takeda K, Yasumoto K, Takada R, Takada S, Watanabe K, Udono T, Saito H, Takahashi K and Shibahara S: Induction of melanocyte-specific microphthalmia-associated transcription factor by Wnt-3a. J Biol Chem 275: 14013-14016, 2000.

28. Widlund HR,Horstmann MA,Price ER,Cui J,Lessnick SL, Wu M, He X and Fisher DE: Beta-catenin-induced melanoma growth requires the downstream target Microphthalmia-associated transcription factor. J Cell Biol 158: 1079-1087, 2002.

29. Martinez-Anton A, Gras D, Bourdin A, Dubreuil P and Chanez P: KIT as a therapeutic target for non-oncological diseases. Pharmacol Ther 197: 11-37, 2019.

30. Niwano T, Terazawa S, Nakajima H and Imokawa G: The stem cell factor-stimulated melanogenesis in human melanocytes can be abrogated by interrupting the phosphorylation of MSK1: Evidence for involvement of the p38/MSK1/CREB/MITF axis. Arch Dermatol Res 310: 187-196, 2018.

31. Li PH, Liu LH, Chang CC, Gao R, Leung CH, Ma DL and David Wang HM: Silencing stem cell factor gene in fibroblasts to regulate paracrine factor productions and enhance c-Kit expression in melanocytes on melanogenesis. Int J Mol Sci 19: pii: E1475, 2018.

32. Flaherty KT, Hodi FS and Fisher DE: From genes to drugs: Targeted strategies for melanoma. Nat Rev Cancer 12: 349-361, 2012.

33. Bonaventure J, Domingues MJ and Larue L: Cellular and molecular mechanisms controlling the migration of melanocytes and melanoma cells. Pigment Cell Melanoma Res 26: 316-325, 2013.

34. Ahn JH, Jin SH and Kang HY: LPS induces melanogenesis through p38 MAPK activation in human melanocytes. Arch Dermatol Res 300: 325-329, 2008.

35. Kim JY, Lee EJ, Ahn Y, Park S, Kim SH and Oh SH: A chemical compound from fruit extract of Juglans mandshurica inhibits melanogenesis through p-ERK-associated MITF degradation. Phytomedicine 57: 57-64, 2019.

36. Hwang E, Lee TH, Lee WJ, Shim WS, Yeo EJ, Kim S and Kim SY: A novel synthetic Piper amide derivative NED-180 inhibits hyperpigmentation by activating the PI3K and ERK pathways and by regulating Ca2+ influx via TRPM1 channels. Pigment Cell Melanoma Res 29: 81-91, 2016.

37. Vance KW and Goding CR: The transcription network regulating melanocyte development and melanoma. Pigment Cell Res 17: $318-325,2004$ 
38. Seberg HE, Van Otterloo E and Cornell RA: Beyond MITF: Multiple transcription factors directly regulate the cellular phenotype in melanocytes and melanoma. Pigment Cell Melanoma Res 30: 454-466, 2017.

39. Price ER, Horstmann MA, Wells AG, Weilbaecher KN Takemoto CM, Landis MW and Fisher DE: alpha-Melanocyte-stimulating hormone signaling regulates expression of microphthalmia, a gene deficient in Waardenburg syndrome. J Biol Chem 273: 33042-33047, 1998.

40. Bondurand N, Pingault V, Goerich DE, Lemort N, Sock E, Le Caignec $\mathrm{C}$, Wegner $\mathrm{M}$ and Goossens $\mathrm{M}$ : Interaction among SOX10, PAX3 and MITF, three genes altered in Waardenburg syndrome. Hum Mol Genet 9: 1907-1917, 2000.

41. Jacquemin P, Lannoy VJ, O'Sullivan J, Read A, Lemaigre FP and Rousseau GG: The transcription factor onecut-2 controls the microphthalmia-associated transcription factor gene. Biochem Biophys Res Commun 285: 1200-1205, 2001

42. Saito H, Yasumoto K, Takeda K, Takahashi K, Fukuzaki A, Orikasa S and Shibahara S: Melanocyte-specific microphthalmia-associated transcription factor isoform activates its own gene promoter through physical interaction with lymphoid-enhancing factor 1 . J Biol Chem 277: 28787-28794, 2002.

43. Hsiao JJ and Fisher DE: The roles of microphthalmia-associated transcription factor and pigmentation in melanoma. Arch Biochem Biophys 563: 28-34, 2014.

44. Hasegawa $T$, Takano F, Takata $T$, Niiyama $M$ and Ohta $T$ : Bioactive monoterpene glycosides conjugated with gallic acid from the leaves of Eucalyptus globulus. Phytochemistry 69 : 747-753, 2008.

45. Choi MH, Jo HG, Yang JH, Ki SH and Shin HJ: Antioxidative and anti-melanogenic activities of bamboo stems (Phyllostachys nigra variety henosis) via PKA/CREB-mediated MITF downregulation in B16F10 melanoma cells. Int J Mol Sci 19: pii: E409, 2018.

46. Yasumoto K, Yokoyama K, Takahashi K, Tomita Y and Shibahara S: Functional analysis of microphthalmia-associated transcription factor in pigment cell-specific transcription of the human tyrosinase family genes. J Biol Chem 272: 503-509, 1997

47. Tachibana M: MITF: A stream flowing for pigment cells. Pigment Cell Res 13: 230-240, 2000.

48. Fang D, Tsuji Y and Setaluri V: Selective down-regulation of tyrosinase family gene TYRP1 by inhibition of the activity of melanocyte transcription factor, MITF. Nucleic Acids Res 30: 3096-3106, 2002.

49. Huang HC, Chang SJ, Wu CY, Ke HJ and Chang TM: [6]-Shogaol inhibits $\alpha$-MSH-induced melanogenesis through the acceleration of ERK and PI3K/Akt-mediated MITF degradation. Biomed Res Int 2014: 842569, 2014

50. Alam MB, Seo BJ, Zhao P and Lee SH: Anti-melanogenic activities of heracleum moellendorffii via ERK1/2-mediated MITF downregulation. Int J Mol Sci 17: pii: E1844, 2016.

51. Zhao P, Alam MB, An H, Choi HJ, Cha YH, Yoo CY, Kim HH and Lee SH: Antimelanogenic effect of an oroxylum indicum seed extract by suppression of MITF expression through activation of MAPK signaling protein. Int J Mol Sci 19: pii: E760, 2018.

52. Wu PY, You YJ, Liu YJ, Hou CW, Wu CS, Wen KC, Lin CY and Chiang HM: Sesamol inhibited melanogenesis by regulating melanin-related signal transduction in B16F10 cells. Int J Mol Sci 19: pii: E1108, 2018.

53. Truong XT, Park SH, Lee YG, Jeong HY, Moon JH and Jeon TI: Protocatechuic acid from pear inhibits melanogenesis in melanoma cells. Int J Mol Sci 18: pii: E1809, 2017.

54. Sun L, Guo Y, Zhang Y and Zhuang Y: Antioxidant and Anti-tyrosinase activities of phenolic extracts from rape bee pollen and inhibitory melanogenesis by cAMP/MITF/TYR pathway in B16 mouse melanoma cells. Front Pharmacol 8: 104 2017.

55. Chen YS, Lee SM, Lin CC and Liu CY: Hispolon decreases melanin production and induces apoptosis in melanoma cells through the downregulation of tyrosinase and microphthalmia-associated transcription factor (MITF) expressions and the activation of caspase-3, -8 and -9. Int J Mol Sci 15: 1201-1215, 2014.

56. Wu QY, Wong ZC, Wang C, Fung AH, Wong EO, Chan GK, Dong TT, Chen Y and Tsim KW: Isoorientin derived from Gentiana veitchiorum Hemsl. flowers inhibits melanogenesis by down-regulating MITF-induced tyrosinase expression. Phytomedicine 57: 129-136, 2019.
57. Seong ZK, Lee SY, Poudel A, Oh SR and Lee HK: Constituents of cryptotaenia japonica inhibit melanogenesis via CREB- and MAPK-associated signaling pathways in murine B16 melanoma cells. Molecules 21: pii: E1296, 2016.

58. Kang SJ, Choi BR, Lee EK, Kim SH, Yi HY, Park HR, Song CH, Lee YJ and $\mathrm{Ku}$ SK: Inhibitory effect of dried pomegranate concentration powder on melanogenesis in B16F10 melanoma cells; involvement of $\mathrm{p} 38$ and PKA signaling pathways. Int J Mol Sci 16: 24219-24242, 2015.

59. Lee HJ, Lee WJ, Chang SE and Lee GY: Hesperidin, A popular antioxidant inhibits melanogenesis via Erk1/2 Mediated MITF degradation. Int J Mol Sci 16: 18384-18395, 2015.

60. Chae JK, Subedi L, Jeong M, Park YU, Kim CY, Kim H and Kim SY: Gomisin N inhibits melanogenesis through regulating the PI3K/Akt and MAPK/ERK signaling pathways in melanocytes. Int J Mol Sci 18: pii: E471, 2017.

61. Su TR, Lin JJ, Tsai CC, Huang TK, Yang ZY, Wu MO, Zheng YQ, Su CC and $\mathrm{Wu} Y \mathrm{~J}$ : Inhibition of melanogenesis by gallic acid: Possible involvement of the PI3K/Akt, MEK/ERK and Wnt $/ \beta$-catenin signaling pathways in B16F10 cells. Int J Mol Sci 14: 20443-20458, 2013.

62. Lee DH, Ahn SS, Kim JB, Lim Y, Lee YH and Shin SY: Downregulation of $\alpha$-melanocyte-stimulating hormone-induced activation of the Pax3-MITF-tyrosinase axis by sorghum ethanolic extract in B16F10 melanoma cells. Int J Mol Sci 19: pii: E1640, 2018.

63. Tsao YT, Huang YF, Kuo CY, Lin YC, Chiang WC, Wang WK, Hsu CW and Lee CH: Hinokitiol inhibits melanogenesis via $\mathrm{AKT} / \mathrm{mTOR}$ signaling in B16F10 mouse melanoma cells. Int J Mol Sci 17: 248, 2016

64. Ko GA, Shrestha S and Kim Cho S: Sageretia thea fruit extracts rich in methyl linoleate and methyl linolenate downregulate melanogenesis via the Akt/GSK3 $\beta$ signaling pathway. Nutr Res Pract 12: 3-12, 2018

65. Lee SJ, Lee WJ, Chang SE and Lee GY: Antimelanogenic effect of ginsenoside $\mathrm{Rg} 3$ through extracellular signal-regulated kinase-mediated inhibition of microphthalmia-associated transcription factor. J Ginseng Res 39: 238-242, 2015.

66. Cho BR, Jun HJ, Thach TT, Wu C and Lee SJ: Betaine reduces cellular melanin content via suppression of microphthalmia-associated transcription factor in B16-F1 murine melanocytes. Food Sci Biotechnol 26: 1391-1397, 2017.

67. Alam MB, Bajpai VK, Lee J, Zhao P, Byeon JH, Ra JS, Majumder R, Lee JS, Yoon JI, Rather IA, et al: Inhibition of melanogenesis by jineol from Scolopendra subspinipes mutilans via MAP-Kinase mediated MITF downregulation and the proteasomal degradation of tyrosinase. Sci Rep 7: 45858, 2017.

68. Hu S, Huang J, Pei S, Ouyang Y, Ding Y, Jiang L, Lu J, Kang L, Huang L, Xiang $\mathrm{H}$, et al: Ganoderma lucidum polysaccharide inhibits UVB-induced melanogenesis by antagonizing cAMP/PKA and ROS/MAPK signaling pathways. J Cell Physiol 234: 7330-7340, 2019.

69. Oh CT, Kwon TR, Jang YJ, Yoo KH, Kim BJ and Kim H: Inhibitory effects of Stichopus japonicus extract on melanogenesis of mouse cells via ERK phosphorylation. Mol Med Rep 16: 1079-1086, 2017.

70. Huang HC, Wei CM, Siao JH, Tsai TC, Ko WP, Chang KJ, Hii CH and Chang TM: Supercritical fluid extract of spent coffee grounds attenuates melanogenesis through downregulation of the PKA, PI3K/Akt and MAPK signaling pathways. Evid Based Complement Alternat Med 2016: 5860296, 2016.

71. Kim JW, Kim HI, Kim JH, Kwon OC, Son ES, Lee CS and Park YJ: Effects of ganodermanondiol, a new melanogenesis inhibitor from the medicinal mushroom ganoderma lucidum. Int J Mol Sci 17: pii: E1798, 2016.

72. Oh TI, Jung HJ, Lee YM, Lee S, Kim GH, Kan SY, Kang H, Oh T, Ko HM, Kwak KC, et al: Zerumbone, a tropical ginger sesquiterpene of zingiber officinale roscoe, attenuates $\alpha-\mathrm{MSH}$-induced melanogenesis in B16F10 cells. Int J Mol Sci 19: pii: E3149, 2018

73. Chang TS: Natural melanogenesis inhibitors acting through the down-regulation of tyrosinase activity. Materials (Basel) 5: $1661-1685,2012$

74. Sánchez-Ferrer A, Rodríguez-López JN, García-Cánovas F and García-Carmona F: Tyrosinase: A comprehensive review of its mechanism. Biochim Biophys Acta 1247: 1-11, 1995.

75. Matoba Y, Kumagai T, Yamamoto A, Yoshitsu H and Sugiyama M: Crystallographic evidence that the dinuclear copper center of tyrosinase is flexible during catalysis. J Biol Chem 281: 8981-8990, 2006 
76. Menter JM, Etemadi AA, Chapman W, Hollins TD and Willis I: In vivo depigmentation by hydroxybenzene derivatives. Melanoma Res 3: 443-449, 1993.

77. Briganti S, Camera E and Picardo M: Chemical and instrumental approaches to treat hyperpigmentation. Pigment Cell Res 16: 101-110, 2003.

78. Kang WH, Chun SC and Lee S: Intermittent therapy for melasma in Asian patients with combined topical agents (retinoic acid, hydroquinone and hydrocortisone): Clinical and histological studies. J Dermatol 25: 587-596, 1998.

79. Guevara IL and Pandya AG: Melasma treated with hydroquinone, tretinoin and a fluorinated steroid. Int J Dermatol 40: 212-215, 2001

80. Badreshia-Bansal S and Draelos ZD: Insight into skin lightening cosmeceuticals for women of color. J Drugs Dermatol 6: 32-39, 2007.

81.Parvez S, Kang M, Chung HS, Cho C, Hong MC, Shin MK and Bae H: Survey and mechanism of skin depigmenting and lightening agents. Phytother Res 20: 921-934, 2006.

82. Haddad AL, Matos LF, Brunstein F, Ferreira LM, Silva A and Costa D Jr: A clinical, prospective, randomized, double-blind trial comparing skin whitening complex with hydroquinone vs. placebo in the treatment of melasma. Int J Dermatol 42: 153-156, 2003.

83. Gupta AK, Gover MD, Nouri K and Taylor S: The treatment of melasma: A review of clinical trials. J Am Acad Dermatol 55 1048-1065, 2006.

84. Kim DS, Park SH, Kwon SB, Li K, Youn SW and Park KC: (-)-Epigallocatechin-3-gallate and hinokitiol reduce melanin synthesis via decreased MITF production. Arch Pharm Res 27 334-339, 2004.

85.Fan M, Zhang G, Hu X, Xu X and Gong D: Quercetin as a tyrosinase inhibitor: Inhibitory activity, conformational change and mechanism. Food Res Int 100: 226-233, 2017.

86. Jones K, Hughes J, Hong M, Jia Q and Orndorff S: Modulation of melanogenesis by aloesin: A competitive inhibitor of tyrosinase. Pigment Cell Res 15: 335-340, 2002.

87. Jin YH, Lee SJ, Chung MH, Park JH, Park YI, Cho TH and Lee SK: Aloesin and arbutin inhibit tyrosinase activity in a synergistic manner via a different action mechanism. Arch Pharm Res 22: 232-236, 1999.

88. Solano F, Briganti S, Picardo M and Ghanem G: Hypopigmenting agents: An updated review on biological, chemical and clinica aspects. Pigment Cell Res 19: 550-571, 2006.

89. Satooka $\mathrm{H}$ and Kubo I: Resveratrol as a kcat type inhibitor for tyrosinase: Potentiated melanogenesis inhibitor. Bioorg Med Chem 20: 1090-1099, 2012.

90.Lee TH, Seo JO, Baek SH and Kim SY: Inhibitory effects of resveratrol on melanin synthesis in ultraviolet B-induced pigmentation in Guinea pig skin. Biomol Ther (Seoul) 22 35-40, 2014

91. Chen J, Yu X and Huang Y: Inhibitory mechanisms of glabridin on tyrosinase. Spectrochim Acta A Mol Biomol Spectrosc 168 111-117, 2016

92.Lin Y, Kuang Y, Li K, Wang S, Song W, Qiao X, Sabir G and Ye M: Screening for bioactive natural products from a 67-compound library of Glycyrrhiza inflata. Bioorg Med Chem 25: 3706-3713, 2017.

93. Fu B, Li H, Wang X, Lee FS and Cui S: Isolation and identification of flavonoids in licorice and a study of their inhibitory effects on tyrosinase. J Agric Food Chem 53: 7408-7414, 2005.

94. Nerya O, Vaya J, Musa R, Izrael S, Ben-Arie R and Tamir S Glabrene and isoliquiritigenin as tyrosinase inhibitors from licorice roots. J Agric Food Chem 51: 1201-1207, 2003

95. Yang SH, Tsatsakis AM, Tzanakakis G, Kim HS, Le B, Sifaki M, Spandidos DA, Tsukamoto C, Golokhvast KS, Izotov BN, et al: Soyasaponin Ag inhibits aMSHinduced melanogenesis in B16F10 melanoma cells via the downregulation of TRP2. Int J Mol Med 40: 631-636, 2017

96. Wang Y, Curtis-Long MJ, Lee BW, Yuk HJ, Kim DW, Tan XF and Park KH: Inhibition of tyrosinase activity by polyphenol compounds from Flemingia philippinensis roots. Bioorg Med Chem 22: 1115-1120, 2014

97. Takahashi M, Takara K, Toyozato T and Wada K: A novel bioactive chalcone of Morus australis inhibits tyrosinase activity and melanin biosynthesis in B16 melanoma cells. J Oleo Sci 61 : 585-592, 2012.

98. Roh JS, Han JY, Kim JH and Hwang JK: Inhibitory effects of active compounds isolated from safflower (Carthamus tinctorius L.) seeds for melanogenesis. Biol Pharm Bull 27: 1976-1978, 2004
99. Liang CP, Chang $\mathrm{CH}$, Liang CC, Hung KY and Hsieh CW: In vitro antioxidant activities, free radical scavenging capacity and tyrosinase inhibitory of flavonoid compounds and ferulic acid from Spiranthes sinensis (Pers.) Ames. Molecules 19: 4681-4694, 2014.

100. Jhan JK, Chung YC, Chen GH, Chang CH, Lu YC and Hsu CK Anthocyanin contents in the seed coat of black soya bean and their anti-human tyrosinase activity and antioxidative activity. Int J Cosmet Sci 38: 319-324, 2016.

101. Jeong HS, Gu GE, Jo AR, Bang JS, Yun HY, Baek KJ, Kwon NS, Park KC and Kim DS: Baicalin-induced Akt activation decreases melanogenesis through downregulation of microphthalmia-associated transcription factor and tyrosinase. Eur J Pharmacol 761: 19-27, 2015.

102. Hwang JA, Park NH, Na YJ, Lee HK, Lee JH, Kim YJ and Lee CS: Coumestrol down-regulates melanin production in melan-a murine melanocytes through degradation of tyrosinase. Biol Pharm Bull 40: 535-539, 2017.

103. de Freitas MM, Fontes PR, Souza PM, William Fagg C, Neves Silva Guerra E, de Medeiros Nóbrega YK, Silveira D, Fonseca-Bazzo Y, Simeoni LA, Homem-de-Mello M, et al: Extracts of Morus nigra L. leaves standardized in chlorogenic acid, rutin and isoquercitrin: Tyrosinase inhibition and cytotoxicity. PLoS One 11: e0163130, 2016.

104. Chen YS, Lee SM, Lin CC, Liu CY, Wu MC and Shi WL: Kinetic study on the tyrosinase and melanin formation inhibitory activities of carthamus yellow isolated from Carthamus tinctorius L. J Biosci Bioeng 115: 242-245, 2013.

105. Nihei KI and Kubo I: Substituent effect of benzaldehydes on tyrosinase inhibition. Plant Physiol Biochem 112: 278-282, 2017.

106. Moghrovyan A, Sahakyan N, Babayan A, Chichoyan N, Petrosyan M and Trchounian A: Essential oil and ethanol extract of oregano (Origanum vulgare L.) from Armenian flora as a natural source of terpenes, flavonoids and other phytochemicals with antiradical, antioxidant, metal chelating, tyrosinase inhibitory and antibacterial activity. Curr Pharm Des 25: 1809-1816, 2019

107. Park HJ, Cho JH, Hong SH, Kim DH, Jung HY, Kang IK and Cho YJ: Whitening and anti-wrinkle activities of ferulic acid isolated from Tetragonia tetragonioides in B16F10 melanoma and CCD-986sk fibroblast cells. J Nat Med 72: 127-135, 2018.

108. Rao AR, Sindhuja HN, Dharmesh SM, Sankar KU, Sarada R and Ravishankar GA: Effective inhibition of skin cancer, tyrosinase and antioxidative properties by astaxanthin and astaxanthin esters from the green alga Haematococcus pluvialis. J Agric Food Chem 61: 3842-3851, 2013.

109. Niwano T, Terazawa S, Nakajima H, Wakabayashi $\mathrm{Y}$ and Imokawa G: Astaxanthin and withaferin A block paracrine cytokine interactions between UVB-exposed human keratinocytes and human melanocytes via the attenuation of endothelin-1 secretion and its downstream intracellular signaling. Cytokine 73: 184-197, 2015.

110. Tu CX, Lin M, Lu SS, Qi XY, Zhang RX and Zhang YY: Curcumin inhibits melanogenesis in human melanocytes. Phytother Res 26: 174-179, 2012.

111. Cabanes J, Chazarra S and Garcia-Carmona F: Kojic acid, a cosmetic skin whitening agent, is a slow-binding inhibitor of catecholase activity of tyrosinase. J Pharm Pharmacol 46: 982-985, 1994

112. Picardo M and Carrera M: New and experimental treatments of cloasma and other hypermelanoses. Dermatol Clin 25: 353-362, ix, 2007.

113. Dooley TP, Gadwood RC, Kilgore K and Thomasco LM Development of an in vitro primary screen for skin depigmentation and antimelanoma agents. Skin Pharmacol 7: 188-200, 1994.

114. Curto EV, Kwong C, Hermersdörfer H, Glatt H, Santis C, Virador V, Hearing VJ Jr and Dooley TP: Inhibitors of mammalian melanocyte tyrosinase: In vitro comparisons of alkyl esters of gentisic acid with other putative inhibitors. Biochem Pharmacol 57: 663-672, 1999.

115. Hsu KD, Chen HJ, Wang CS, Lum CC, Wu SP, Lin SP and Cheng KC: Extract of ganoderma formosanum mycelium as a highly potent tyrosinase inhibitor. Sci Rep 6: 32854, 2016.

116. Peng CC, Sun HT, Lin IP, Kuo PC and Li JC: The functional property of royal jelly 10-hydroxy-2-decenoic acid as a melanogenesis inhibitor. BMC Complement Altern Med 17: 392, 2017. 
117. Chen WC, Tseng TS, Hsiao NW, Lin YL, Wen ZH, Tsai CC, Lee YC, Lin HH and Tsai KC: Discovery of highly potent tyrosinase inhibitor, T1, with significant anti-melanogenesis ability by zebrafish in vivo assay and computational molecular modeling. Sci Rep 5: 7995, 2015.

118. Chang TS and Chen CT: Inhibitory effect of homochlorcyclizine on melanogenesis in $\alpha$-melanocyte stimulating hormone-stimulated mouse B16 melanoma cells. Arch Pharm Res 35: 119-127, 2012.

119. Newton RA, Cook AL, Roberts DW, Leonard JH and Sturm RA: Post-transcriptional regulation of melanin biosynthetic enzymes by cAMP and resveratrol in human melanocytes. J Invest Dermatol 127: 2216-2227, 2007.

120. Ando H, Wen ZM, Kim HY, Valencia JC, Costin GE, Watabe H, Yasumoto K, Niki Y, Kondoh H, Ichihashi M, et al: Intracellular composition of fatty acid affects the processing and function of tyrosinase through the ubiquitin-proteasome pathway. Biochem J 394: 43-50, 2006

121.Park SH, Kim DS, Kim WG, Ryoo IJ, Lee DH, Huh CH, Youn SW, Yoo ID and Park KC: Terrein: A new melanogenesis inhibitor and its mechanism. Cell Mol Life Sci 61: 2878-2885, 2004

122.Lee S, Kim WG, Kim E, Ryoo IJ, Lee HK, Kim JN, Jung SH and Yoo ID: Synthesis and melanin biosynthesis inhibitory activity of (+/-)-terrein produced by Penicillium sp. 20135. Bioorg Med Chem Lett 15: 471-473, 2005.

123. Cheung FW, Guo J, Ling YH, Che CT and Liu WK: Anti-melanogenic property of geoditin A in murine B16 melanoma cells. Mar Drugs 10: 465-476, 2012.

124. Minwalla L, Zhao Y, Cornelius J, Babcock GF, Wickett RR, Le Poole IC and Boissy RE: Inhibition of melanosome transfer from melanocytes to keratinocytes by lectins and neoglycoproteins in an in vitro model system. Pigment Cell Res 14: 185-194, 2001.

125. Seiberg M: Keratinocyte-melanocyte interactions during melanosome transfer. Pigment Cell Res 14: 236-242, 2001.

126. Hakozaki T, Minwalla L, Zhuang J, Chhoa M, Matsubara A, Miyamoto K, Greatens A, Hillebrand GG, Bissett DL and Boissy RE: The effect of niacinamide on reducing cutaneous pigmentation and suppression of melanosome transfer. Br J Dermatol 147: 20-31, 2002.

127.Paine C, Sharlow E, Liebel F, Eisinger M, Shapiro S and Seiberg M: An alternative approach to depigmentation by soybean extracts via inhibition of the PAR-2 pathway. J Invest Dermatol 116: 587-595, 2001.

128. Wallo W, Nebus J and Leyden JJ: Efficacy of a soy moisturizer in photoaging: A double-blind, vehicle-controlled, 12 week study. J Drugs Dermatol 6: 917-922, 2007.

129. Lee CS, Nam G, Bae IH and Park J: Whitening efficacy of ginsenoside F1 through inhibition of melanin transfer in cocultured human melanocytes-keratinocytes and three-dimensional human skin equivalent. J Ginseng Res 43: 300-304, 2019.

130. Kuroda TS and Fukuda M: Rab27A-binding protein Slp2-a is required for peripheral melanosome distribution and elongated cell shape in melanocytes. Nat Cell Biol 6: 1195-1203, 2004

131. Wu XS, Rao K, Zhang H, Wang F, Sellers JR, Matesic LE, Copeland NG, Jenkins NA and Hammer JA III: Identification of an organelle receptor for myosin-Va. Nat Cell Biol 4: 271-278, 2002
132. Kudo M, Kobayashi-Nakamura $K$ and Tsuji-Naito $K$ : Bifunctional effects of O-methylated flavones from Scutellaria baicalensis Georgi on melanocytes: Inhibition of melanin production and intracellular melanosome transport. PLoS One 12: e0171513, 2017.

133. Lee HY, Jang EJ, Bae SY, Jeon JE, Park HJ, Shin J and Lee SK: Anti-melanogenic activity of gagunin D, a Highly Oxygenated Diterpenoid from the Marine Sponge Phorbas sp., via Modulating Tyrosinase Expression and Degradation. Mar Drugs 14: pii: E212, 2016.

134. Ando H, Ryu A, Hashimoto A, Oka M and Ichihashi M: Linoleic acid and alpha-linolenic acid lightens ultraviolet-induced hyperpigmentation of the skin. Arch Dermatol Res 290: 375-381, 1998.

135. Yoshimura K, Tsukamoto K, Okazaki M, Virador VM, Lei TC, Suzuki Y, Uchida G, Kitano Y and Harii K: Effects of all-trans retinoic acid on melanogenesis in pigmented skin equivalents and monolayer culture of melanocytes. J Dermatol Sci 27 (Suppl 1): S68-S75, 2001

136. Yoshimura K, Harii K, Aoyama T, Shibuya F and Iga T: A new bleaching protocol for hyperpigmented skin lesions with a high concentration of all-trans retinoic acid aqueous gel. Aesthetic Plast Surg 23: 285-291, 1999.

137. Ramos-e-Silva M, Hexsel DM, Rutowitsch MS and Zechmeister M: Hydroxy acids and retinoids in cosmetics. Clin Dermatol 19: 460-466, 2001

138. Gupta AK, Gover MD, Nouri K and Taylor S: The treatment of melasma: A review of clinical trials. J Am Acad Dermatol 55: 1048-1065, 2006.

139. Amer M and Metwalli M: Topical liquiritin improves melasma. Int J Dermatol 39: 299-301, 2000.

140. Virador VM, Kobayashi N, Matsunaga J and Hearing VJ: A standardized protocol for assessing regulators of pigmentation. Anal Biochem 270: 207-219, 1999.

141. Lei TC, Virador VM, Vieira WD and Hearing VJ: A melanocyte-keratinocyte coculture model to assess regulators of pigmentation in vitro. Anal Biochem 305: 260-268, 2002.

142. Hermanns JF, Petit L, Piérard-Franchimont C, Paquet P and Piérard GE: Assessment of topical hypopigmenting agents on solar lentigines of asian women. Dermatology 204: 281-286, 2002.

143. Tengamnuay P, Pengrungruangwong K, Pheansri I and Likhitwitayawuid K: Artocarpus lakoocha heartwood extract as a novel cosmetic ingredient: Evaluation of the in vitro anti-tyrosinase and in vivo skin whitening activities. Int $\mathbf{J}$ Cosmet Sci 28: 269-276, 2006.

144. Alexis AF and Blackcloud P: Natural ingredients for darker skin types: Growing options for hyperpigmentation. J Drugs Dermatol 12 (9 Suppl): s123-s127, 2013.

This work is licensed under a Creative Commons Attribution-NonCommercial-NoDerivatives 4.0 International (CC BY-NC-ND 4.0) License. 